\title{
Prevalence of Pseudomonas aeruginosa in Surgical Site Infection in a Tertiary Care Centre
}

\author{
Sapana Mundhada, Anu Sharma, KishorIngole and Sadiya Shaikh \\ Department of Microbiology, Dr. V.M. Government Medical College Solapur-413003, \\ Maharashtra India \\ *Corresponding author
}

\begin{tabular}{|c|c|}
\hline & $A B S T R A C T$ \\
\hline & \multirow{6}{*}{$\begin{array}{l}\text { Pseudomonas aeruginosa is a leading cause of nosocomial infections. Infections caused by } \\
\text { it are often severe and life threatening and difficult to treat because the organism is } \\
\text { inherently resistant to many drug classes (MDR) and is able to acquire resistance to all } \\
\text { effective antimicrobial drugs. Over the years, P. aeruginosa contributes substantially to } \\
\text { morbidity and mortality related to surgical site infection (SSI) worldwide, the third most } \\
\text { commonly reported nosocomial infection. People infected with drug-resistant organisms } \\
\text { like } P \text {. aeruginosa are more likely to have longer and more expensive hospital stays, and } \\
\text { may be more likely to die as a result of the infection. The study was aimed to determine } \\
\text { the prevalence and drug resistance pattern of } P \text {. aeruginosa in SSI. Over a } 2 \text {-year period, } \\
\text { specimens were received as postoperative wound swabs in Microbiology department and } \\
\text { processed for isolation and identification of bacterial pathogens, according to the standard } \\
\text { microbiological techniques. Antibiotic Sensitivity test was performed on Mueller Hinton } \\
\text { agar by Kirby Bauer's disc diffusion method. Out of } 360 \text { bacterial organism isolated, } 68 \\
\text { (18.89 \%) were } P \text {. aeruginosa. A total of } 11 \text { ( } 16.18 \% \text { ) isolates were resistant to three or } \\
\text { more antibiotic classes (multidrug resistance). Imipenem and piperacillin/tazobactam } \\
\text { showed high sensitivity, with } 88.24 \% \text { and } 89.71 \% \text { respectively. Continued monitoring of } \\
\text { susceptibility pattern of } P \text {. aeruginosa from SSI need to be carried out in individual } \\
\text { settings so as to detect the true burden of multidrug resistance in organisms and prevent } \\
\text { their further emergence by judicious use of drugs. }\end{array}$} \\
\hline Keywords & \\
\hline $\begin{array}{l}\text { Surgical site infection } \\
\text { (SSI), P. aeruginosa, } \\
\text { Antimicrobial } \\
\text { susceptibility testing. }\end{array}$ & \\
\hline Article Info & \\
\hline $\begin{array}{l}\text { Accepted: } \\
12 \text { March } 2017 \\
\text { Available Online: } \\
10 \text { April } 2017\end{array}$ & \\
\hline & \\
\hline
\end{tabular}

\section{Introduction}

Among Surgical patients, surgical site infection (SSI) is an important cause of health care associated infection (Ranjan et al., 2010). They account for approximately a quarter of nosocomial infection.

SSI have been responsible for increasing cost of treatment due to prolong hospital stay as well as high morbidity and mortality related to surgical operation and continue to be major problem even in hospital with most Morden facility and standard protocols of preoperative preparation and antibiotic prophylaxis (Lilani et al., 2005). Incidence of SSI in India ranges from $4.04 \%$ to $30 \%$ (More et al., 2015).

The virulence factor and invasive property of the microorganisms are the important risk factor for development of infection, but the physiological state of the tissue in the wound and immunological integrity of the host also shows equal importance in determining whether infection occurs or not (Ranjan et al., 2010). The common pathogenic bacteria 
isolated from SSI include Staphylococci, Pseudomonas, Streptococci, Enterococci, E.coli, Klebsiella, Enterobacter, Citrobacter, Acinetobacter, Proteus, etc (Naik et al., 2011).

In the recent years, increasing incidence of $P$. aeruginosa in SSI is a serious problem in developing countries as infections caused by it are often severe and life threatening and difficult to treat because the organism is inherently resistant to many drug classes (MDR) either intrinsically or following acquisition of resistant gene thus reducing treatment options for patients. Also $P$. aeruginosa shows variety of virulence factors like lipopolysaccharides (LPSs), exotoxin A, leucocidin, extracellular slime, proteases, phospholipase, and several other enzymes which make it the most clinically significant pathogen among non-fermenting bacteria. Pseudomonas aeruginosa is a leading cause of nosocomial infection, ranking second among gram-negative pathogens as reported by the United States national nosocomial infection surveillance system. $P$. aeruginosa contributes substantially to SSIrelated morbidity and mortality worldwide. So the present study was aimed to determine the prevalence of $P$. aeruginosa in the isolates of postoperative wounds infection in our setting and its antimicrobial susceptibility pattern.

\section{Materials and Methods}

The present study was carried out at a tertiary care centre in the Microbiology department from January 2015 to December 2016.Two wound swabs were collected aseptically from all clinically suspected cases of SSI from all surgical wards, one swab was used for Gram stain and the other for culture. All the collected swabs were processed for detection of aerobic bacteria without delay in the following manner (Collee et al., 2006; Forbes et al., 2007). a. Gram stain microscopy by $1^{\text {st }}$ swab.

b. Inoculation on culture media by using $2^{\text {nd }}$ swab (Blood agar, MacConkey agar).

c. Preliminary identification of the growth (Gram stain, catalase test, oxidase test, motility, etc.).

d. Routine standard biochemical tests for confirm identification.

e. Antimicrobial susceptibility testing by Kirby Bauer disk diffusion method (Performance Standards for Antimicrobial Susceptibility Testing, 2015).

Antibiotic testing was not done of other bacterial isolates in this study since our focus was on the prevalence of $P$. aeruginosa. Antibiotics used in our study were piperacillin $(100 \mu \mathrm{g})$, ceftazidime $(30 \mu \mathrm{g})$, imipenem $(10$ $\mu \mathrm{g})$, piperacillin/tazobactam $(100 / 10 \mu \mathrm{g}))$, gentamicin $(10 \mu \mathrm{g})$, cefepime $(30 \mu \mathrm{g})$ and ciprofloxacin $(5 \mu \mathrm{g})$.

\section{Results and Discussion}

Total 360 specimen were obtained from postoperative wound infection patients admitted in surgery, orthopaedics, Obstetrics and gynaecology ward. Among them 278 $(77.22 \%)$ sample revealed growth while $82(22.78 \%)$ showed no growth. Pseudomonas aeruginosa 68(18.89\%) was the most common isolate followed by $E$. coli 58 (16.11\%), Klebsiella spp.53 (14.72\%), Staphylococcus aureus 46(12.78\%), Proteus spp.32 (8.89\%) and Acinetobacter spp 21(5.84\%). Pseudomonas aeruginosa had showed maximum susceptibility to Pipracillin-Tazobactam $(89.71 \%)$ and Imipenem (88.24\%) (Table 1).

Out of 68 P. aeruginosa 11(16.18\%) were resistant to three or more class of drug 
(MDR). Frequency of isolation of $P$. aeruginosa was maximum in patients who underwent caesarean section followed by abscess drainage and Diabetic foot (Table 2). We found that $P$. aeruginosa infection was more common in age group 21-40 years and males $(54.41 \%)$ were more affected than female $(45.59 \%)$.

Surgical site infection (SSI) is an important cause of health care associated infection among surgical patients. Patients who developed SSI have longer hospital stay, more expensive hospitalization and increased morbidity and mortality. In present study $77.22 \%$ sample had shown growth of aerobic bacteria. Similar finding were observed in other studies by Insan et al., (2013) and More et al., (2015). Pseudomonas aeruginosa $68(18.89 \%)$ was the most common bacteria isolated in our study followed by $E$. coli 58 (16.11\%), Klebsiella spp.53 (14.72\%), Staphylococcus aureus 46(12.78\%) which can be correlated well with the findings of other studies byRanjan et al., (2010) and Lilani et al., (2005) while Negi et al., (2015) found $E$. coli as common isolate and Mundhada et al., (2015) reported $S$. aureus as predominant organism in their studies. When factors such as age and sex of the patient were considered, $P$. aeruginosa was found to be more common in males than female and highest in the age group 21-40 years which can be correlates with results recorded by Ranjan et al., (2010) and More et al., (2015).

Table.1 The susceptibility pattern of $P$. aeruginosa isolated from post-operative wound swab $(\mathrm{n}=68)$

\begin{tabular}{|c|c|}
\hline Antibiotic & Percentage of susceptibility (\%) \\
\hline piperacillin/tazobactam & $61(89.71 \%)$ \\
\hline Imipenem & $60(88.24 \%)$ \\
\hline Piperacillin & $47(69.12 \%)$ \\
\hline Ceftazidime & $42(61.76 \%)$ \\
\hline Gentamicin & $21(30.88 \%)$ \\
\hline Cefepime & $18(26.47 \%)$ \\
\hline Ciprofloxacin & $12(17.64 \%)$ \\
\hline
\end{tabular}

Table.2 Prevalence of $P$. aeruginosa isolated from different type of surgeries

\begin{tabular}{|c|c|c|c|}
\hline Type of Surgery & $\begin{array}{c}\text { Total no. of } \\
\text { specimens }\end{array}$ & $\begin{array}{c}\text { Total no of } \boldsymbol{P} . \\
\text { aeruginosa isolated }\end{array}$ & Percentage (\%) \\
\hline Cesarean section & 91 & 26 & $38.25 \%$ \\
\hline Abscess drainage & 77 & 19 & $27.68 \%$ \\
\hline Diabetic foot & 66 & 10 & $14.70 \%$ \\
\hline Abdominal abscess & 27 & 8 & $11.76 \%$ \\
\hline Bone excision & 17 & 5 & $7.35 \%$ \\
\hline
\end{tabular}


Fig.1 Pigment production of P. aeruginosa on Nutrient Agar

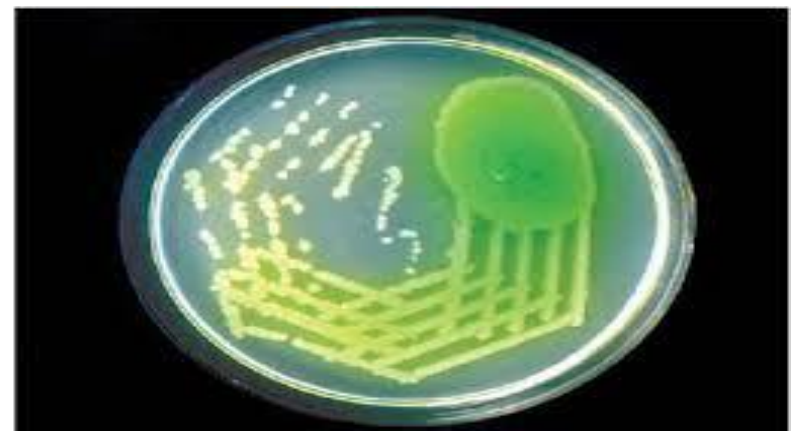

Antimicrobial susceptibility pattern of $P$. aeruginosa shows highest sensitivity to Pipracillin-Tazobactam followed by imipenem while maximum resistance to ciprofloxacin, cefepime and Gentamicin. Similar results were recorded by Ranjan et al, Navneet et al., and Mohamad et al., (Ranjan et al., 2010; Navaneeth et al., 2002; Mahmoud et al., 2013). In present study, out of $68 \quad P$. aeruginosa $11(16.18 \%)$ were resistant to three or more class of drug (MDR). Similar finding were recorded in study by Mohamad et al., (2013) (10.60\%) while in contrast Srinivas et al., (2012) reported $86.90 \%$ MDR $P$. aeruginosa in their study. In our study, $P$. aeruginosa isolation rate was highest from patients who underwent caesarean section followed by abscess drainage and Diabetic foot. In contrast to this Ranjan et al., (2010) isolated $P$. aeruginosa mainly from patients of abscess drainage followed by Diabetic foot and caesarean section.

In conclusion, SSI is major risk in surgeries in spite of use of modern surgical and sterilization technique and use of prophylactic antibiotic during surgery. SSI represent substantial burden of disease not only on patient but also on health care services in terms of morbidity, mortality and the economic costs. According to our study, continued monitoring of susceptibility pattern of $P$. aeruginosa from SSI need to be carried out in individual settings so as to detect the true burden of multidrug resistance in organisms and prevent their further emergence by judicious use of drugs.

\section{References}

Collee, J.G., Miles, R.S., Watt, B. 2006. Laboratory strategy in the diagnosis of infective syndrome. In: Colle JG, Fraser AG, Marimon BP, Simmons A, editors. Mackie and McCartney Practical Medical Microbiology. 14th ed. Edinburg: Elsevier Churchill Livingstone; p. 84-90.

Forbes, B.A., Sahm, D.F., Weissfeld, A.S. 2007. Overview of bacterial identification methods and strategies. Bailey and Scott's Diagnostic Microbiology. 12th ed. Missouri: Mosby Elsevier; p. 218-47.

Lilani, S.P., Jangale, N., Chowdhary, A., Daver, G.B. 2005. Surgical site infections in clean and clean contaminated cases. IJMM, 23(4): 24952.

Mahmoud, A.B., Zahran, W.A., Hindawi, G.R., Labib, A.Z., Galal, R. 2013. Prevalence of Multidrug-Resistant Pseudomonas aeruginosa in Patients with Nosocomial Infections at a University Hospital in Egypt, with Special Reference to Typing Methods. J. Virol. Microbiol., 1-13.

More, S.R., Kale, C.D., Shrikhande, S.N., Rathod, V.S., Kasturi. 2015. 
Bacteriological profile of surgical site infection among postoperative patients at a tertiary care centre in Nanded. Int. J. Adv. Res., Vol 3(11): 1060 -66.

Mundhada, A.S., Tenpe, S. 2015. A study of organisms causing surgical site infections and their antimicrobial susceptibility in a tertiary care government Hospital. Indian J. Pathol. Microbiol., 58(2): 195-200.

Naik, G., Deshpande, S.R. 2011. A Study on Surgical Site Infections Caused by Staphylococcus aureus with Search for Methicillin-Resistant Isolates. J. Clin. Diag. Res., Vol-5(3): 502-8.

Navaneeth, B.V., Sridaran, D., Sahay, D., Belwadi, M.R. 2002. A preliminary study on metallo-beta-lactamase producing Pseudomonas aeruginosa in hospitalized patients. Indian J. Med. Res., 116: 264-7.

Negi, V., Pal, S., Juyal, D., et al. 2015. Bacteriological profile of surgical site infections and their antibiogram: a study from resource constrained rural setting of Uttarakhand state, India. J. Clin. Diagn. Res., 9(10): DC17-DC20.

Nitin GoelInsan, Nikhil Payal, Mahesh Singh, Amod Yadav, B.L. Chaudhary, Ambrish Srivastava. 2013. Postoperative wound infection: bacteriology and antibiotic sensitivity pattern. Int. J. Curr. Res. Rev., Vol 05(13): 74-77.

Performance Standards for Antimicrobial Susceptibility Testing. 2015. Twentyfifth Informational Supplement. CLSI document M100-S25. Wayne, PA: Clinical and Laboratory Standards Institute.

Ranjan, K.P., Ranjan, N., Bansal, S.K., Arora, D.R. 2010. Prevalence of Pseudomonas aeruginosa in Post-operativeWound Infection in a Referral Hospital in Haryana, India. J. Lab. Physicians, Vol2(2): 74-7

Srinivas, B., Devi, D.L., Rao, B.N. 2012. A prospective study of $P$. aeruginosa and its antibiograms in teaching hospital of Rural setup. JPBMS, Vol 22(18): 1-5.

\section{How to cite this article:}

Sapana Mundhada, Anu Sharma, KishorIngole, Sadiya Shaikh. 2017. Prevalence of Pseudomonas aeruginosa in Surgical Site Infection in a Tertiary Care Centre. Int.J.Curr.Microbiol.App.Sci. 6(4): 1202-1206. doi: https://doi.org/10.20546/ijcmas.2017.604.147 